\title{
NUCLEAR ANALYSIS OF THE FIRE IGNITION DEVICE
}

\author{
M.E. Sawan and H.Y. Khater \\ University of Wisconsin \\ Fusion Technology Institute \\ 1500 Engineering Dr.
}

(608) 263-5093

\begin{abstract}
Neutronics and activation calculations have been performed for the FIRE design with different first wall design options. Modest values of nuclear heating occur in the machine components. Magnet insulators that have radiation tolerance to 150 MGy should be used. The operational schedule allows for decay of short-lived radionuclides between pulses resulting in low levels of activity and decay heat at shutdown. Additional shielding is provided in midplane ports and at the top of the machine to allow for hands-on maintenance of ex-vessel components.
\end{abstract}

\section{INTRODUCTION}

The Fusion Ignition Research Experiment (FIRE) is a compact high field tokamak that utilizes cryogenically cooled copper coils. ${ }^{1}$ It has a major radius of $2 \mathrm{~m}$ and an aspect ratio of 3.8. The device is expected to achieve a high fusion power gain, Q, of 10 . A double walled vacuum vessel (VV) with integral shielding has been adopted. A cross sectional view of the FIRE tokamak is given in Fig. 1. The design is in the pre-conceptual phase with different design options and operating scenarios being considered.

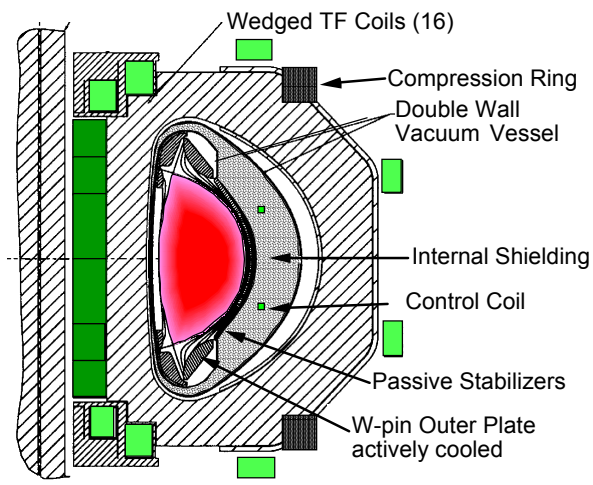

Fig. 1. Cross section of FIRE.

The FIRE operation schedule includes DD and DT pulses with different fusion powers and pulse widths. DT pulses with fusion powers as high as $200 \mathrm{MW}$ producing a total of $5 \mathrm{TJ}$ of fusion energy are planned. In addition, DD pulses with different widths and fusion powers up to 1 MW are expected to yield total fusion energy of $0.5 \mathrm{TJ}$. The baseline pulse length at $10 \mathrm{~T}$ is $18.5 \mathrm{~s}$ with the possibility of upgrading to $12 \mathrm{~T}$ field, reducing the pulse length to $12 \mathrm{~s}$. In addition, the toroidal and poloidal field magnets are capable of extending pulse lengths at lower fields to explore advanced tokamak modes. For longer pulses it might be necessary to actively cool the entire divertor and the first wall (FW). Nuclear analysis is essential at this stage to evaluate the impact of design options and assess if the major performance objectives of the project can be met without jeopardizing performance of the radiation sensitive components.

\section{CALCULATION APPROACH}

Two design options are considered for the FW/tiles: Option 1 with passive cooling and Option 2 with active water cooling. The FW/tiles on the inboard (IB) side for Option 1 consist of a $0.5 \mathrm{~cm}$ plasma facing component (PFC) $(90 \% \mathrm{Be})$, followed by $4.3 \mathrm{~cm} \mathrm{Cu}$ tiles $(80 \%$ $\mathrm{CuCrZr}$ alloy) and a $0.2 \mathrm{~cm}$ gasket $(50 \% \mathrm{SiC})$. In Option 2 , the IB FW/tiles consist of $0.5 \mathrm{~cm} \mathrm{Be}$ PFC $(90 \% \mathrm{Be})$, $1.8 \mathrm{~cm} \mathrm{Cu}$ tiles $(80 \% \mathrm{CuCrZr}), 0.2 \mathrm{~cm}$ gasket $(50 \% \mathrm{Cu})$, and $2.5 \mathrm{~cm}$ water-cooled $\mathrm{Cu}(80 \% \mathrm{CuCrZr}, 15 \%$ water $)$. For the outboard (OB) side, the same radial build is used except that the total thickness is increased to $10 \mathrm{~cm}$ in Option 1. The impact of these design options on nuclear heating in the different components and the $\mathrm{VV}$ and magnet shielding was assessed.

The detailed radial build of the outer divertor plate was used in the analysis. The front layer is a $0.5 \mathrm{~cm} \mathrm{~W}$ Brush $(90 \% \mathrm{~W})$ followed by a $0.1 \mathrm{~cm}$ region $(84 \% \mathrm{~W}, 14 \%$ $\mathrm{CuCrZr}, 2 \%$ void) where the $\mathrm{W}$ rods are joined to the $\mathrm{Cu}$ heat sink. The $1.9 \mathrm{~cm}$ heat sink is made of $\mathrm{Cu}$ finger plates (78\% $\mathrm{CuCrZr}$, 20\% water, $2 \%$ void). A $3 \mathrm{~cm}$ region $(47 \%$ $\mathrm{CuCrZr}, 48 \% \mathrm{SS} 316,5 \%$ void) represents the mechanical attachment between the $\mathrm{Cu}$ finger plates and the $7 \mathrm{~cm}$ thick backing plate ( $84 \%$ SS316, $16 \%$ water).

The VV consists of $1.5 \mathrm{~cm}$ thick inner and outer facesheets made of $316 \mathrm{SS}$. The space between the VV facesheets (VV shielding zone) includes 60\% 304SS and $40 \%$ water except in the IB region where $11 \% 304 \mathrm{SS}$ and 
$89 \%$ water is used because of the small thickness. The thicknesses of the VV in the IB midplane, OB midplane, and divertor region are 5, 54, and $12 \mathrm{~cm}$, respectively. A $1.5 \mathrm{~cm}$ thick layer of thermal insulation (10\% Microtherm insulation) is attached to the back of the coil-side VV facesheet. The $\mathrm{Cu}$ TF coils are included in the model with OFHC $\mathrm{Cu}$ alloy at a $90 \%$ packing factor. A 304SS coil case is used in the $\mathrm{OB}$ region with $4 \mathrm{~cm}$ front thickness and $6 \mathrm{~cm}$ back thickness. Both the IB and $\mathrm{OB}$ regions were modeled simultaneously to account for the toroidal effects.

Neutronics and shielding calculations were performed using the ONEDANT module of the DANTSYS 3.0 discrete ordinates particle transport code system. ${ }^{2}$ Activation analysis was performed using the DKRPULSAR2.0 activation code system. ${ }^{3}$ The FENDL-2 data was used in both neutronics and activation calculations.

\section{NUCLEAR HEATING}

Nuclear heating deposited in the different components was determined and used in the thermal analysis. The largest nuclear heating values in the different components were calculated for the $200 \mathrm{MW}$ fusion power DT pulses. During these pulses the average neutron wall loading is 3 $\mathrm{MW} / \mathrm{m}^{2}$ with values at the OB midplane, IB midplane, and divertor being $3.6 \mathrm{MW} / \mathrm{m}^{2}, 2.7 \mathrm{MW} / \mathrm{m}^{2}$, and 1.8 $\mathrm{MW} / \mathrm{m}^{2}$, respectively. For the DD pulses with the largest fusion power $(1 \mathrm{MW})$, nuclear heating values are less than $1 \%$ of the values for the 200 MW DT pulses. Table 1 gives the peak power density values at the chamber midplane for the two FW/tiles design options. The peak nuclear heating values in the FW/tiles are comparable for the two design options. The IB VV and magnet heating values decrease by $\sim 15 \%$ in Option 2 because of the added water coolant in the $\mathrm{FW}$ and using $\mathrm{Cu}$ in the gasket in place of $\mathrm{SiC}$. The $\mathrm{OB} \mathrm{VV}$ and magnet heating values increase by a factor of $1.5-2$ in Option 2, primarily due to the $5 \mathrm{~cm}$ reduction in the $\mathrm{FW} /$ tiles thickness. The largest power density values in the magnet occur in the IB region at midplane. Figure 2 gives the nuclear heating distribution in the passively cooled $\mathrm{OB} \mathrm{FW} / \mathrm{tiles}$ at midplane Nuclear heating in the VV drops by an order of magnitude in $\sim 18 \mathrm{~cm}$. Nuclear heating in the IB magnet drops by an order of magnitude in $\sim 28 \mathrm{~cm}$. This relatively weak attenuation is due to the toroidal geometry effects. Table 2 lists the peak nuclear heating values calculated in the different components at the top and bottom of the machine. Relatively high nuclear heating is deposited in the W PFC. Figure 3 shows the nuclear heating distribution in the outer divertor plate.

The total nuclear heating in the $16 \mathrm{TF}$ coils for 200 MW DT fusion power was estimated based on the results of the 1-D calculations taking into account the poloidal variation of neutron wall loading, shielding thickness, and magnet toroidal coverage. Table 3 gives the breakdown of total magnet nuclear heating for the two FW/tiles design options. The total heating is dominated by contribution from the lightly shielded IB legs. The total magnet heating decreases by $14 \%$ in Option 2 compared to Option 1 because of the added water coolant in the FW and using $\mathrm{Cu}$ in the gasket in place of $\mathrm{SiC}$.

Table 1. Peak Nuclear Heating $\left(\mathrm{W} / \mathrm{cm}^{3}\right)$ at Midplane

\begin{tabular}{|l|c|c|c|c|}
\hline \multirow{2}{*}{} & \multicolumn{2}{|c|}{$\begin{array}{c}\text { Option 1 } \\
\text { (Passively Cooled }\end{array}$} & \multicolumn{2}{c|}{$\begin{array}{c}\text { Option 2 } \\
\text { (Actively Cooled } \\
\text { FW) }\end{array}$} \\
\cline { 2 - 5 } & IB & OB & IB & OB \\
\hline Be PFC & 34.7 & 36.8 & 33.3 & 35.6 \\
\hline Cu Tiles & 44.9 & 43.6 & 46.9 & 46.3 \\
\hline Gasket & 19.6 & 11.0 & 40.6 & 40.6 \\
\hline Cooled Cu FW & NA & NA & 40.2 & 40.1 \\
\hline $\mathrm{H}_{2}$ O FW Coolant & NA & NA & 27.6 & 30.9 \\
\hline SS Inner VV Wall & 35.9 & 19.6 & 33.8 & 30.9 \\
\hline SS VV Filer & 37.5 & 20.6 & 32.9 & 28.5 \\
\hline $\mathrm{H}_{2} \mathrm{O}$ VV Coolant & 17.5 & 11.1 & 14.9 & 15.5 \\
\hline SS Outer VV Wall & 35.1 & 0.04 & 30.3 & 0.07 \\
\hline Microtherm Insul. & 11.4 & 0.01 & 9.8 & 0.02 \\
\hline SS Inner Coil Case & NA & 0.021 & NA & 0.038 \\
\hline Cu Magnet & 23.1 & 0.010 & 19.5 & 0.019 \\
\hline SS Outer Coil Case & NA & $1.5 \times 10^{-5}$ & NA & $2.8 \times 10^{-5}$ \\
\hline
\end{tabular}

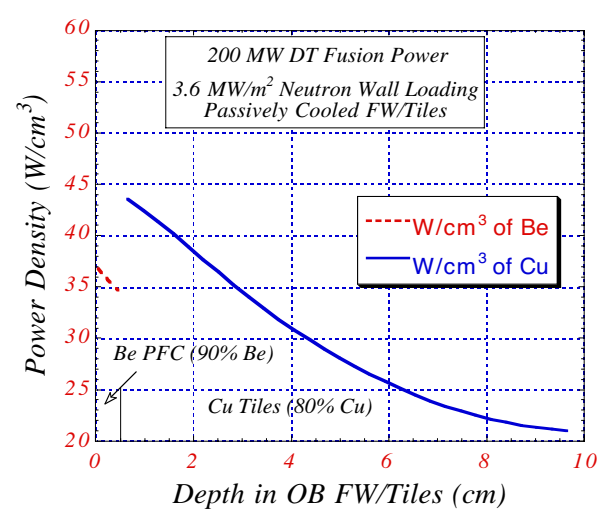

Fig. 2. Nuclear heating distribution in the OB FW/tiles.

Table 2. Nuclear Heating in the Divertor Region

\begin{tabular}{|c|c|}
\hline & Peak Nuclear heating $\left(\mathrm{W} / \mathrm{cm}^{3}\right)$ \\
\hline W divertor PFC & 49.0 \\
\hline $\mathrm{Cu}$ divertor heat sink & 17.2 \\
\hline SS divertor structure & 14.9 \\
\hline SS VV & 6.7 \\
\hline Magnet & 1.7 \\
\hline
\end{tabular}

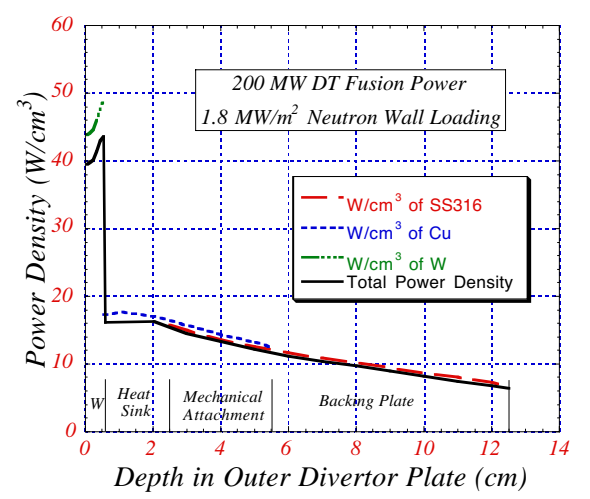

Fig 3. Nuclear heating in the divertor region. 
Table 3. Total Magnet Nuclear Heating

\begin{tabular}{|c|c|c|}
\hline & \multicolumn{2}{|c|}{ Magnet Nuclear Heating (MW) } \\
\hline & Option 1 & Option 2 \\
\hline IB region & 27 & 22.9 \\
\hline OB region & 0.03 & 0.05 \\
\hline Divertor region & 2.1 & 2.1 \\
\hline Total & 29.13 & 25.05 \\
\hline
\end{tabular}

\section{RADIATION DAMAGE}

The peak cumulative end-of-life radiation damage values were calculated for the FW/tiles, VV, divertor, and magnet. For the operation scenario of total DT fusion energy of $5 \mathrm{TJ}$ and total DD fusion energy of $0.5 \mathrm{TJ}$, the dpa values are very low $(<0.05 \mathrm{dpa})$ and will not limit the lifetime of these components. Since the VV is protected from the fusion neutrons by the thin FW/tiles, the issue of reweldability was addressed. The end-of-life helium production in the VV structure should be limited to $1 \mathrm{appm}$ to allow for rewelding. ${ }^{4}$ Table 4 gives the results at different poloidal locations for the passively and actively cooled FW/tiles design options. The contribution from DD shots is very small $(<0.15 \%)$. The VV helium production for Option 1 peaks in the IB region since the FW/tiles is 5 $\mathrm{cm}$ thinner than in the $\mathrm{OB}$ region. In Option 2 , the $\mathrm{FW} /$ tiles thickness is the same in both regions and the higher OB neutron wall loading results in higher VV He production in the $\mathrm{OB}$ region. Lower $\mathrm{VV}$ He production occurs in the divertor region as a result of shielding by the relatively thick divertor plate. The IB VV He production decreases by $15 \%$ in Option 2 because of the added water coolant in the FW. The OB VV He production increases by a factor of $\sim 2$ in Option 2 due to the $5 \mathrm{~cm}$ reduction in FW/tiles thickness. The results imply that reweldability of the VV should not be a concern with both design options.

Table 4. Peak End-of-life He Production (appm) in VV

\begin{tabular}{|l|c|c|}
\hline & Option 1 & Option 2 \\
\hline IB midplane & 0.13 & 0.11 \\
\hline OB midplane & 0.07 & 0.15 \\
\hline Divertor & 0.016 & 0.016 \\
\hline
\end{tabular}

\section{MAGNET INSULATOR DOSE}

The insulator dose rate in the $\mathrm{TF}$ magnet was calculated at the front layer of the magnet winding pack. For $5 \mathrm{TJ}$ of DT fusion energy and $0.5 \mathrm{TJ}$ of DD fusion energy, Table 5 provides the peak cumulative magnet insulator dose. The peak value occurs in the lightly shielded IB side at midplane. The dose rate decreases as one moves poloidally to the OB midplane. The neutron contribution to the insulator dose varies between $50 \%$ at the front of the winding pack to $30 \%$ at the back. The relative contribution from DD shots decreases as one moves poloidally from the IB midplane to the $\mathrm{OB}$ midplane due to increased attenuation of low energy DD neutrons. The peak cumulative insulator dose decreases by
$14 \%$ in Option 2 compared to Option 1 because of the added water coolant in the FW and using $\mathrm{Cu}$ in the gasket.

The mechanical strength, dielectric strength, and electric resistivity are the important properties that could be affected by irradiation. The shear strength is the property most sensitive to irradiation. The commonly accepted dose limit for epoxies is $10^{9}$ Rads. ${ }^{4}$ Polyimides and bismaleimides are more radiation resistant with experimental data showing only a small degradation in shear strength at dose levels in excess of $10^{10}$ Rads. However, they are difficult to process due to their high viscosity and requirement for high temperatures to fully cure. Hybrids of polyimides or bismaleimides and epoxies could provide radiation resistant insulators with easier processing requirements. The availability, properties, and manufacturing impact of using these insulators will be investigated. $^{5}$

The results presented here were obtained by performing 1-D calculations. Based on previous studies, accurate modeling of the chamber geometry and source profile in a 3-D calculation results in about $20 \%$ lower peak IB results. ${ }^{6}$ In addition, in the FIRE design, the peak shear stresses occur at the top and bottom of the TF coil IB leg behind the divertor. The end-of-life dose to the insulator at this location is reduced to $\sim 10^{9}$ Rads due to the additional shielding provided by the divertor. The insulator dose decreases as one moves radially from the front to the back of the winding pack as shown in Fig. 4 . Based on this analysis, it is expected that insulation materials will be identified that can last for the whole device lifetime with the proposed operation scenario.

Table 5. Cumulative Peak Magnet Insulator Dose (Rads)

\begin{tabular}{|l|c|c|c|}
\hline & Option 1 & Option 2 & $\begin{array}{c}\% \text { from DD } \\
\text { Shots }\end{array}$ \\
\hline IB midplane & $1.47 \times 10^{10}$ & $1.26 \times 10^{10}$ & $13 \%$ \\
\hline OB midplane & $6.97 \times 10^{6}$ & $1.26 \times 10^{7}$ & $1.6 \%$ \\
\hline Divertor & $9.80 \times 10^{8}$ & $9.80 \times 10^{8}$ & $10 \%$ \\
\hline
\end{tabular}

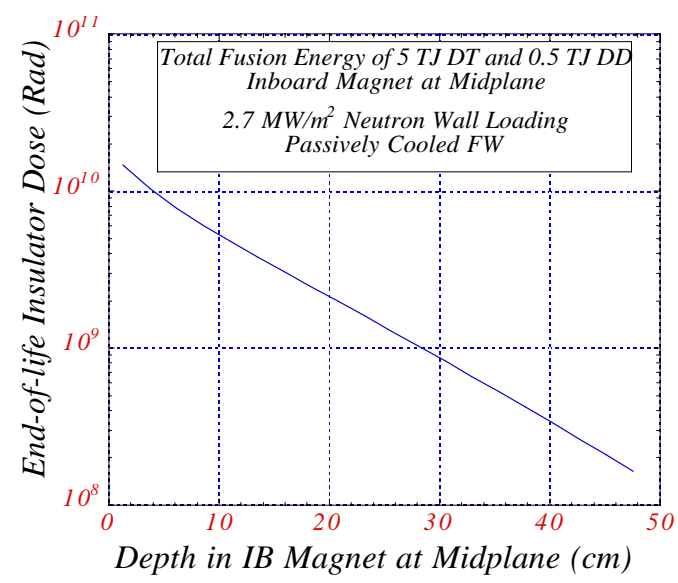

Fig. 4. Radial variation of insulator dose in IB magnet. 


\section{ACTIVITY AND DECAY HEAT}

In the activation calculations, the machine is assumed to have an operation schedule of four pulses per day with a pulse length of 20 seconds and 3 hours between pulses. Calculations were performed for DT and DD shots with 200 MW and 1 MW of fusion power, respectively. The levels of activity and decay heat generated in the two $\mathrm{FW} /$ tiles design options are comparable. Figure 5 shows the specific decay heat values generated in the IB region for design option 1. The plasma facing components on the FW and divertor produce the highest levels of specific activity and decay heat. However, the operational schedule with several hours between pulses allows for the decay of short-lived radionuclides between pulses, resulting in low levels of activity and decay heat at shutdown.

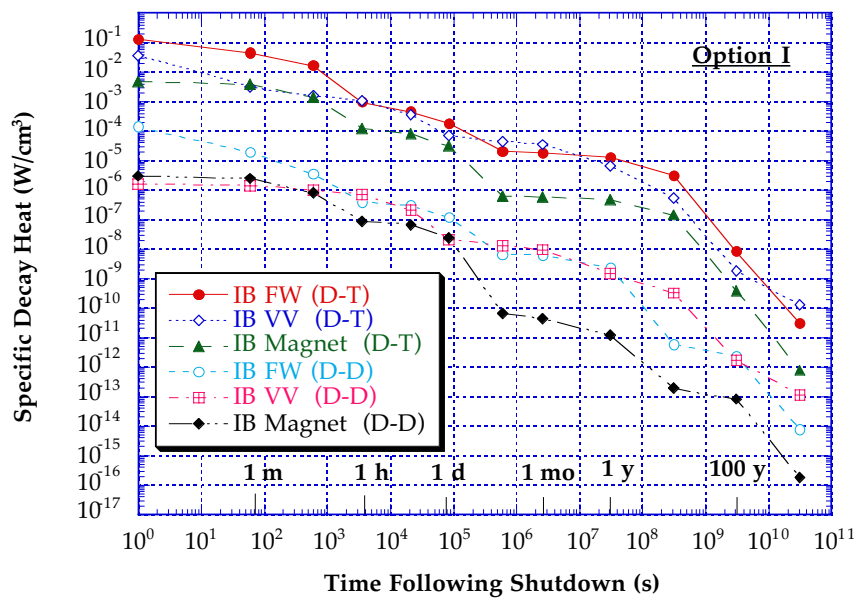

Fig. 5. Decay heat in IB side for design option 1.

At shutdown, the decay heat induced in the $\mathrm{FW}$ following DT shots is less than $0.25 \%$ of the nuclear heating generated during operation. In the mean time, the ratio between the shutdown decay heat and operational nuclear heating generated in the VV is $0.1 \%$. The activity and decay heat generated following DD shots are at least three orders of magnitude lower than their values following DT shots. The decay heat induced in the FW at shutdown is dominated by the copper isotopes ${ }^{62} \mathrm{Cu}\left(\mathrm{T}_{1 / 2}=9.74 \mathrm{~min}\right)$ and ${ }^{66} \mathrm{Cu}\left(\mathrm{T}_{1 / 2}=5.1 \mathrm{~min}\right)$. Their short lifetimes allow them to decay during the three hours between pulses yielding low levels of decay heat following pulses. The decay heat induced in the $\mathrm{VV}$ at shutdown is dominated by the ${ }^{52} \mathrm{~V}\left(\mathrm{~T}_{1 / 2}=3.76 \mathrm{~min}\right)$ and ${ }^{56} \mathrm{Mn}\left(\mathrm{T}_{1 / 2}=2.578 \mathrm{hr}\right)$ isotopes. Due to the short lifetime of ${ }^{52} \mathrm{~V}$, its entire radioactivity also decays between shots. In general, the short-term activity and decay heat values at shutdown are almost fully dominated by activation during the last pulse.

\section{BIOLOGICAL DOSE RATES}

In order to assess the feasibility of hands-on maintenance, biological dose rates were calculated at different locations following shutdown. The gamma source from radioactive decay was determined at all mesh points and transported, using the ONEDANT code, to calculate dose rates at different locations following shutdown.

Figure 6 shows the biological dose rates at the midplane as a function of time following DT shots. The biological dose rates behind the $\mathrm{VV}$ remain high for several years following shutdown. On the other hand, in the case of DD shots, the dose rates behind the VV are five orders of magnitude lower than after DT shots allowing for hands-on maintenance behind the VV. The dose rates behind the magnet at midplane are acceptable for both DD and DT shots. The thinner OB FW in Option 2 results in dose rates that are about twice those in Option 1. Dose rates behind the magnet are caused by the ${ }^{6 \mathrm{~m}} \mathrm{Co}\left(\mathrm{T}_{1 / 2}=13.9\right.$ $\mathrm{min}$ ) isotope and are independent on the number of pulses due to the fact that ${ }^{62 \mathrm{~m}} \mathrm{Co}$ decays between pulses. One week following shutdown, the dose rates are dominated by the ${ }^{60} \mathrm{Co}\left(\mathrm{T}_{1 / 2}=5.27 \mathrm{yr}\right)$ isotope and will linearly increase with number of pulses. Neutron streaming through the large midplane ports results in excessive dose rates. Our results indicate that using a $110 \mathrm{~cm}$ thick steel shield plug in these ports will provide adequate shielding that allows for hands-on maintenance.



Fig. 6. Biological dose rates at midplane.

The dose rate at the top of the machine (at the maximum divertor thickness) following DT shots (Fig. 7), drops to an acceptable level within a day following shutdown. Adding a $20 \mathrm{~cm}$ thick POLY/CAST shield at the top drops the dose rate at the top of the shield to acceptable levels only a few hours earlier. However, since the divertor thickness is much smaller at other locations, it is essential to maintain the same shield thickness to guarantee hands-on maintenance at all locations at the top of the machine. The shield is composed of a POLY/CAST mix placed inside a steel tank (the tank wall is $1 \mathrm{~cm}$ thick). The activation of the outer wall of the steel tank results in the generation of ${ }^{56} \mathrm{Mn}$. The dose rates at the top of the machine following DD shots are very low, allowing for immediate access to that space following shots. 


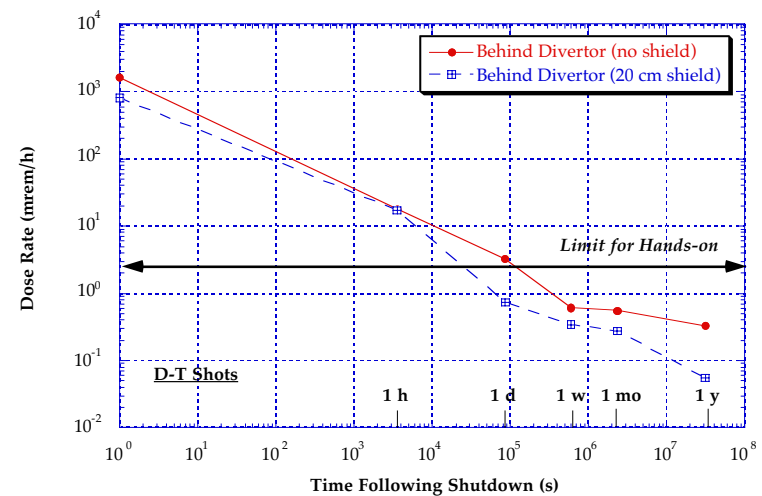

Fig. 7. Biological dose rates at machine top.

\section{WASTE DISPOSAL RATINGS}

The radwaste of the different components of the machine were evaluated according to both the NRC 10CFR $61^{7}$ and Fetter ${ }^{8}$ waste disposal concentration limits. At the end of the machine life, all components would qualify for disposal as Class $\mathrm{C}$ low level waste. The IB FW has the largest waste disposal rating (WDR). It is 0.2 using Fetter limits and 0.02 with the 10CFR61 limits. According to Fetter limits, the WDRs are dominated by the silver impurities in the $\mathrm{CuCrZr}$ alloy and the niobium impurities in the 316SS and 304SS alloys. The 10CFR61 limits indicate that the WDR values of components made of the $\mathrm{CuCrZr}$ alloy are dominated by ${ }^{63} \mathrm{Ni}$ which is produced from copper by the $(n, p)$ reaction. On the other hand, the WDR values of components made of the steel alloys are dominated by their niobium impurities.

\section{SUMMARY}

Neutronics calculations have been performed at different poloidal locations of the FIRE machine for two FW/tiles design options. Nuclear heating profiles during the high DT fusion power pulses were determined to assess cooling needs for the different components. The cumulative end-of-life damage is very low and will not limit the lifetime of the chamber components with the VV being reweldable. The peak IB VV and magnet heating and damage decrease by $\sim 15 \%$ with actively cooled FW/tiles because of the added water coolant in the FW. The total nuclear heating in the $16 \mathrm{TF}$ coils during a $200 \mathrm{MW}$ DT pulse is $\sim 29$ MW for passively cooled FW/tiles and $\sim 25$ MW for actively cooled FW/tiles. The peak end-of-life magnet insulator dose is about $150 \mathrm{MGy}$. About $13 \%$ of the dose is contributed by the DD shots. With the present machine configuration, insulators that have radiation tolerance up to that dose level should be used.

Detailed activation analysis was performed for DT and DD pulses that are $20 \mathrm{~s}$ wide and 3 hours apart. The operational schedule allows for decay of short-lived radionuclides between pulses resulting in low levels of activity and decay heat. In general, the short-term activity and decay heat values are dominated by activation during the last pulse. The results are comparable for both FW/tiles design options. At end-of-life of the machine all components can be disposed of as Class C low level waste. To assess the feasibility of hands-on maintenance, biological dose rates were calculated at different locations following shutdown. The results showed that the biological dose rates behind the VV and the divertor remain high for several years following DT shots. On the other hand, these areas can be immediately accessed following the DD shots. The VV jacket/shield thickness, in conjunction with the shielding provided by the TF coils, port plugs, and top shield is such that hands-on exvessel maintenance will be permitted within a few hours after shutdown.

\section{ACKNOWLEDGEMENT}

Support for this work was provided by the U.S. Department of Energy.

\section{REFERENCES}

1. R. Thome, "Engineering Overview of the Fusion Ignition Research Experiment (FIRE)," Proc. IEEE $18^{\text {th }}$ Symposium on Fusion Engineering, Albuquerque, NM, Oct. 25-29 1999, IEEE Cat. No. 99CH37050, pp. 163.

2. R.E. Alcouffe et al., "DANTSYS 3.0, One-, Two-, and Three-Dimensional Multigroup Discrete Ordinates Transport Code System," RSICC Computer Code Collection CCC-547, Contributed by Los Alamos National Lab, August 1995.

3. J. Sisolak, et al., "DKR-PULSAR2.0: A Radioactivity Calculation Code that Includes Pulsed/Intermittent Operation," to be published.

4. Technical Basis for the ITER Final Design Report, Cost Review and Safety Analysis, ITER EDA Documentation Series, International Atomic Energy Agency, Vienna, December 1997.

5. M.L. Tupper et al., "Magnet Insulation with Resistance to High Levels of Radiation," Proceedings of the 16th International Conference on Magnet Technology, Jacksonville, FL, September 1999.

6. L.A. El-Guebaly, "Nuclear Issues and Analysis for ARIES Spherical and Advanced Tokamaks," Proc. $5^{\text {th }}$ Symposium on Fusion Nuclear Technology, Rome, September 19-24, 1999 (To be published in Fusion Engineering \& Design).

7. Nuclear Regulatory Commission, 10CFR part 61, "Licensing Requirements for Land Disposal of Radioactive Waste," Federal Register, FR 47, 57446 (1982).

8. S. Fetter, E. Cheng and F. Mann, "Long Term Radioactive Waste from Fusion Reactors," Fusion Engineering and Design, 13, 239 (1990). 